\section{B. A. Stemerdink}

J. J. van der Meere

M. W. van der Molen

A. F. Kalverboer

M. M. T. Hendrikx

J. Huisman

L. W. A. van der Schot

F. M. E. Slijper

F. J. van Spronsen

P. H. Verkerk

\title{
Information processing in patients with early and continuously-treated phenylketonuria
}

Received: 6 September 1994

Accepted: 7 February 1995

B. A. Stemerdink ( $\varangle)$

J. J. van der Meere - A. F. Kalverboer

Department of Developmental

and Experimental Clinical Psychology,

State University Groningen,

Grote Kruisstraat 2-I,

9712 TS Groningen, The Netherlands

Tel.: $(+31) 50-636409$

Fax: $(+31) 50-636304$

M. W. van der Molen

Department of Psychology,

University of Amsterdam,

Amsterdam, The Netherlands

M. M. T. Hendrikx

Department of Child Psychiatry,

University Hospital AMC,

Amsterdam, The Netherlands

\section{J. Huismann}

Department of Medical Psychology,

Free University Hospital,

Amsterdam, The Netherlands

L. W. A. van der Schot

Department of Child Psychology,

University Hospital St. Radboud,

Nijmegen, The Netherlands

F. M. E. Slijper

Department of Child

and Adolescent Psychiatry,

Sophia Childrens Hospital,

Rotterdam, The Netherlands

\section{F. J. van Spronsen}

Beatrix Child Clinic,

University Hospital of Groningen,

The Netherlands

\section{P. H. Verkerk}

TNO Institute of Preventive Health Care,

Leiden, The Netherlands
Abstract A total of 33 patients with early and continuousiy-treated phenylketonuria (PKU) between 7 and 16 years of age and 33 matched controls participated in a study examining perceptual, central, and response-related mechanisms of information processing. The specific mechanisms studied were: perceptual filtering, memory search, response selection, response execution, and motor presetting. In addition, groups were compared on mean intelligence level and task oriented behaviour. The performance of the PKU patients practically matched that of the controls on all three tasks, suggesting that PKU patients who are continuously maintained on a well-controlled phenylalanine-restricted diet are not impaired in the elementary mechanisms of information processing. Furthermore, groups did not differ in mean IQ or task-oriented behaviour.

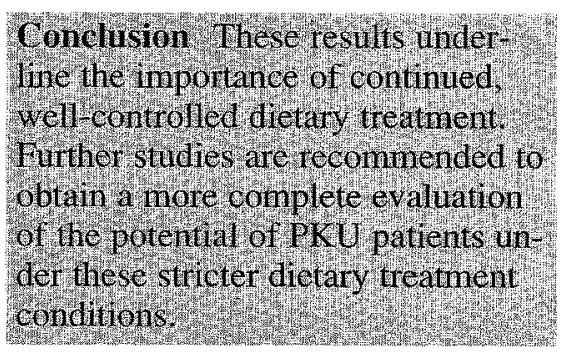

Key words Phenylketonuria. Information processing - Dietary treatment

\section{Abbreviations $P K U$}

phenylketonuria $\cdot P h e$ phenylalanine $I Q$ intelligence quotient $\cdot I S I$ inter-stimulus interval - WISC-R Revised Wechsler Intelligence Scale for Children 


\section{Introduction}

Recent findings indicate that although the mean IQ of early-treated phenylketonuria (PKU) patients falls within the normal range $[5,10,20]$, it tends to be slightly but significantly lower than the mean IQ of their unaffected family members and the mean expected in the general population [15]. In addition, an increased prevalence of behavioural problems $[11,25,26]$, learning disabilities $[13,23]$, cognitive deficits $[4,5,6,24,31]$, and attentional problems $[1,6,7,14,28,29]$ has been noted in patients with early-treated PKU, which cannot be accounted for solely by their slightly lower level of intelligence. Together these findings suggest that, despite the beneficial effects of widespread newborn screening programmes and treatment follow up programmes on the outcome of PKU patients, some degree of impairment may be inevitable. However, since in most of these studies subjects had been off the phenylalanine (Phe)-restricted diet for some time or were still on the diet but with relatively poor control, it remains unclear whether the same results will be obtained in patients who are treated continuously, according to a currently recommended [16] stricter dietary programme.

The main purpose of this study was to examine cognitive functioning in patients with early and continuouslytreated PKU using a chronometric approach to explore elementary information processing mechanisms. Global measures, such as intelligence tests, can be helpful in identifying a more general depression in cognitive functioning but they are relatively inadequate to detect the more subtle differences that might be expected in our sample. Application of an information processing paradigm [19] may enable us to delineate some of the underlying processes that give rise to the PKU-control differences in cognitive functioning, if indeed they are found. In this paradigm, cognitive processing is conceptualized in terms of a sequence of processing stages which take time. By manipulating task variables that selectively operate upon different processing stages, the successive stages of information processing can be studied separately and systematically.

In the present study, PKU patients and matched controls performed three different tasks designed to probe perceptual, central, and response related mechanisms in the chain of information processing. The tasks are sensitive to developmental differences in normal children [21] and have proved to differentiate between normal children, children with attentional deficit hyperactivity disorder, and children with learning disabilities $[17,18]$. All PKU patients had been treated early and continuously, aiming at currently recommended [16] Phe levels between 200 and $480 \mu \mathrm{mol} / \mathrm{l}$. Since previous reports have shown that the speed of performance of PKU patients depends critically on their Phe levels $[28,29]$, information processing efficiency was examined in relationship to the patients' Phe level. In addition, data on intelligence level and task oriented behaviour were obtained for both groups to allow for a more complete evaluation of the effectiveness of stricter dietary treatment.

\section{Subjects and methods}

Subjects

A total of 33 (17 male and 16 female) patients with early-treated PKU between 7 and 16 years of age were recruited from four treatment centres in the Netherlands (Amsterdam, Rotterdam, Nijmegen, and Groningen). Patients were included in this study if they had a diagnosis of classical PKU and were not mentally retarded (a Full Scale IQ < 70). Classical PKU was diagnosed if patients had a pre-treatment serum Phe level $\geq 500 \mu \mathrm{mol} / \mathrm{l}$ and a tolerance for dietary Phe $\leq 50 \mathrm{mg} / \mathrm{kg}$ body weight at 1 year of age. All patients had been continuously maintained on a Phe-restricted diet and participated in the PKU follow up programme [10]. On average, patients had been treated since the 3 rd week of life (range 6-34 days).

The original sample consisted of 58 patients between 7 and 16 years of age. From this sample 3 patients were excluded from participation because they had a full scale IQ $<70$. From the remaining 55 patients, 37 agreed to participate in this study, 6 refused cooperation, 2 did not attend the assessment appointment, and 10 were unable to participate for various practical reasons (e.g. transport, illness, scheduling problems). Four patients were omitted from the analyses because no matched control was available.

The control group consisted of 33 children, recruited from two regular elementary schools and one regular secondary school. Controls were matched individually with patients in the earlytreated PKU.group, according to age, gender, and educational level of both parents. Informed consent was obtained from the parents of the subjects and from all subjects over 10 years of age. The study was approved by the ethical committees of the treatment centres.

\section{Procedure}

Since all PKU patients in our sample had been examined on a regular basis according to the follow up study design, their IQ scores were obtained from the records. The IQ of the matched controls was assessed within 1 month after task administration. The IQ scores of both groups were assessed using the full Dutch version of the Wechsler Intelligence Test for Children - Revised (WISC-R). In addition, teachers of children still in elementary school were asked to fill out a 30 item behaviour rating scale [12]. This rating scale was designed to assess classroom behaviour, which is directly observable by teachers in a normal elementary school situation. An item score can vary from a minimum of 1 (never occurs) to a maximum of 4 (occurs very often). The items can be grouped into five clusters of classroom behaviour: extraversion, introversion, socially negative behaviour, positive task orientation and negative task orientation. We were specifically interested in the last category, because it provides information about behaviour characteristics associated with attentional problems: distractibility, impulsivity, hyperactivity, talkativeness, fluctuating performance [11]. The score that could be obtained on negative task orientation ranged from 4 to 32 , with a norm score of 15.3 (sd 5.4). Children with attentional deficit hyperactivity disorder received a rating of 23.2 (sd 4.1) [12]. Completed behaviour rating scales were returned for 16 matched pairs of subjects.

PKU patients were tested at the treatment centre in their neigh bourhood, where their blood Phe level could be measured. Subjects in the control group were tested at their own school. To maintain consistency in the test administration across subject groups, all subjects were tested by the same experimenter (B.A.S.).

The tasks were administered individually on a Macintosh Classic computer. This computer recorded the speed and the accuracy 
Table 1 Task conditions presented in the Eriksen and Schultz task

\begin{tabular}{|c|c|c|c|}
\hline \multirow{2}{*}{$\begin{array}{l}\text { Target } \\
\text { size }\end{array}$} & \multirow{2}{*}{$\begin{array}{l}\text { Stimulus } \\
\text { congruity }\end{array}$} & \multicolumn{2}{|l|}{ Response type } \\
\hline & & Right button & Left button \\
\hline $\begin{array}{l}\text { Normal } \\
\text { target }\end{array}$ & $\begin{array}{l}\text { Congruent } \\
\text { Incongruent } \\
\text { Neutral }\end{array}$ & 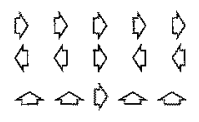 & 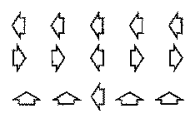 \\
\hline $\begin{array}{l}\text { Small } \\
\text { target }\end{array}$ & $\begin{array}{l}\text { Congruent } \\
\text { Incongruent } \\
\text { Neutral }\end{array}$ & 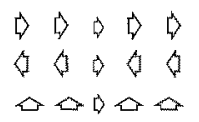 & $\begin{array}{lllll}0 & \langle & 0 & 0 & 0 \\
0 & 0 & 0 & 0 & 0 \\
0 & 0 & 0 & 0\end{array}$ \\
\hline
\end{tabular}

of the responses for each trial. The ' $/$ ' and the ' $Z$ ' were marked on the keyboard as the right and the left response key respectively. Subjects were instructed to respond as quickly as possible without making any errors. The three tasks took about $2 \mathrm{~h}$ to complete.

Tasks

The first task was based on the Eriksen and Schultz flanker paradigm [9] and was designed to assess the efficiency of perceptual filtering (i.e., extract a target stimulus from a distracting surrounding) and response execution (i.e., initiate the correct response in the presence of competing responses). In this task subjects were presented with a row of five arrows and had to respond to the central arrow. This target arrow could point in two directions (right or left), each signalling a different response (pressing the right or pressing the left button, respectively). Congruent, incongruent, and neutral trials were presented to manipulate the efficiency of response execution. In congruent trials the target arrow was flanked by arrows pointing in the same direction, eliciting the same response as the target. In incongruent trials the target was flanked by arrows pointing in the opposite direction, eliciting an opposite response. In neutral trials the target was flanked by arrows pointing upwards, eliciting no response at all (see Table 1). A response execution deficit in PKU patients would be demonstrated by a significant interaction of trial type (congruent, incongruent, neutral) and group (PKU, control) on mean response times.

Perceptual filtering of information was assessed by manipulating the target size. If the target is smaller than the flankers, it is more difficult to extract the target from the noise, which will result in prolonged response times and/or an increased number of incorrect responses. This effect will be especially pronounced in incongruent trials, where the information presented by the flankers is in conflict with the information presented by the target. A perceptual filtering deficit in PKU patients is predicted to produce a significant interaction between the effects of target size (normal, small) and group (PKU, control) on mean response times. The two task manipulations, stimulus congruity and target size, were factorially combined to produce six task conditions, each consisting of 30 trials.

The second task was a variant of the Sternberg memory search task [30] which was introduced by Brookhuis et al [2]. In this task the demands on the central processing mechanisms of memory search (i.e., determine whether a stimulus belongs to a previously provided memory set) and response selection (i.e., select the correct response from two alternative responses) were varied. Two load conditions were used in this task: an easy load condition, in which subjects had to remember a memory set of one item and compare it with a display set of four items, and a difficult load condition, in which subjects bad to remember a memory set of two items and compare it with a display set of four items. Items were consonants measuring $1.5 \mathrm{~cm}$. Subjects were instructed to give a "yes" response if one of the items in both sets matched, and a "no"
Table 2 Phe levels in the PKU sample

\begin{tabular}{lcr}
\hline & Mean & Range \\
\hline First 4 years: & & \\
mean Phe level & 408 & $222-650$ \\
$\%<120 \mu \mathrm{mol} / 1$ & 19.0 & $4.7-39.1$ \\
$\%<200 \mu \mathrm{mol} / 1$ & 34.3 & $9.3-64.3$ \\
$\%>480 \mu \mathrm{mol} / 1$ & 26.5 & $4.3-56.1$ \\
$\%>600 \mu \mathrm{mol} / 1$ & 18.4 & $1.5-42.5$ \\
2 years before the test day: & & \\
mean Phe level & 374 & $125-701$ \\
$\%<120 \mu \mathrm{mol} / \mathrm{l}$ & 13.9 & $0.0-64.3$ \\
$\%<200 \mu \mathrm{mol} / 1$ & 27.8 & $0.0-85.7$ \\
$\%>480 \mu \mathrm{mol} / 1$ & 29.8 & $0.0-100.0$ \\
$\%>600 \mu \mathrm{mol} / \mathrm{l}$ & 16.5 & $0.0-71.4$ \\
\hline
\end{tabular}

response if none of the items matched. Increasing the cognitive load has been demonstrated to prolong the duration of the memory search mechanism [30]. If patients with PKU are limited in their memory search capacity, we would expect them to have a much steeper increase in their mean response time and number of errors as memory load increases, compared to controls.

The response selection mechanism was manipulated by using two probability conditions: a baseline condition in which yes and no responses were equally probable $(50-50)$, and an experimental condition in which the probability of a yes response was reduced to $25 \%$ (25-75). In the latter condition, subjects will prepare for the most frequent (no) response, which is assumed to facilitate the selection of the response. The effect of the probability manipulation will be smaller if patients with PKU are deficient in their ability to select a response. The two task manipulations, memory set size and response probability, were factorially combined to produce four task conditions, each consisting of 64 trials.

The third task was the stimulus interval task designed primarily to examine the efficiency of motor presetting, which can be assessed by manipulating the time between stimulus presentations (inter-stimulus interval [ISI]). The general finding is that shorter intervals facilitate motor presetting and thus response speed. The difference between these response times is considered an index of motor presetting [18].

In this study the inter-stimulus interval was 1,4 , or $8 \mathrm{~s}$. The subject was instructed to press the right button if the letter "P" was presented on the right side of the display, and the left button if the " $\mathrm{P}$ " was presented on the left side of the display. If the letter " $R$ " was presented, no responses were allowed (i.e. catch trials). The P$\mathrm{R}$ ratio was $80-20$. The number of trials in each condition was adjusted to keep the administration times constant at about $8 \mathrm{~min}$, which resulted in 292 trials in the fast condition, 120 in the medium, and 60 in the slow condition.

\section{Biochemical control}

The following biochemical data were considered for statistical analysis in each PKU patient: the mean of monthly blood Phe levels for the period between diet initiation and the age of 4 years [27] and for the 2 years preceding the day of testing (see Table 2). For the same periods we computed the percentage of Phe levels that were outside the Dutch target range, that is, the percentage of Phe levels below $200 \mu \mathrm{mol} / 1$ and the percentage of Phe levels above $480 \mu \mathrm{mol} / \mathrm{l}$. In addition, we computed the percentage of Phe levels considered too low [25] (Phe $<120 \mu \mathrm{mol} / \mathrm{l})$ and the percentage of Phe levels above $600 \mu \mathrm{mol} / /$ [29] (see Table 2). 
Table 3 Group characteristics (mean, range, and SD)

a Paired $t$-test $(\mathrm{df}=32)$

b Paired $t$-test $(\mathrm{df}=15$ )

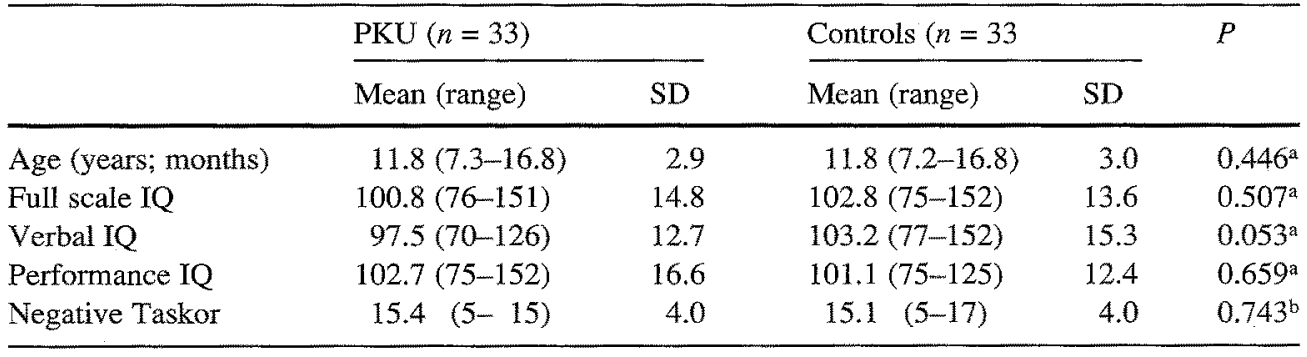

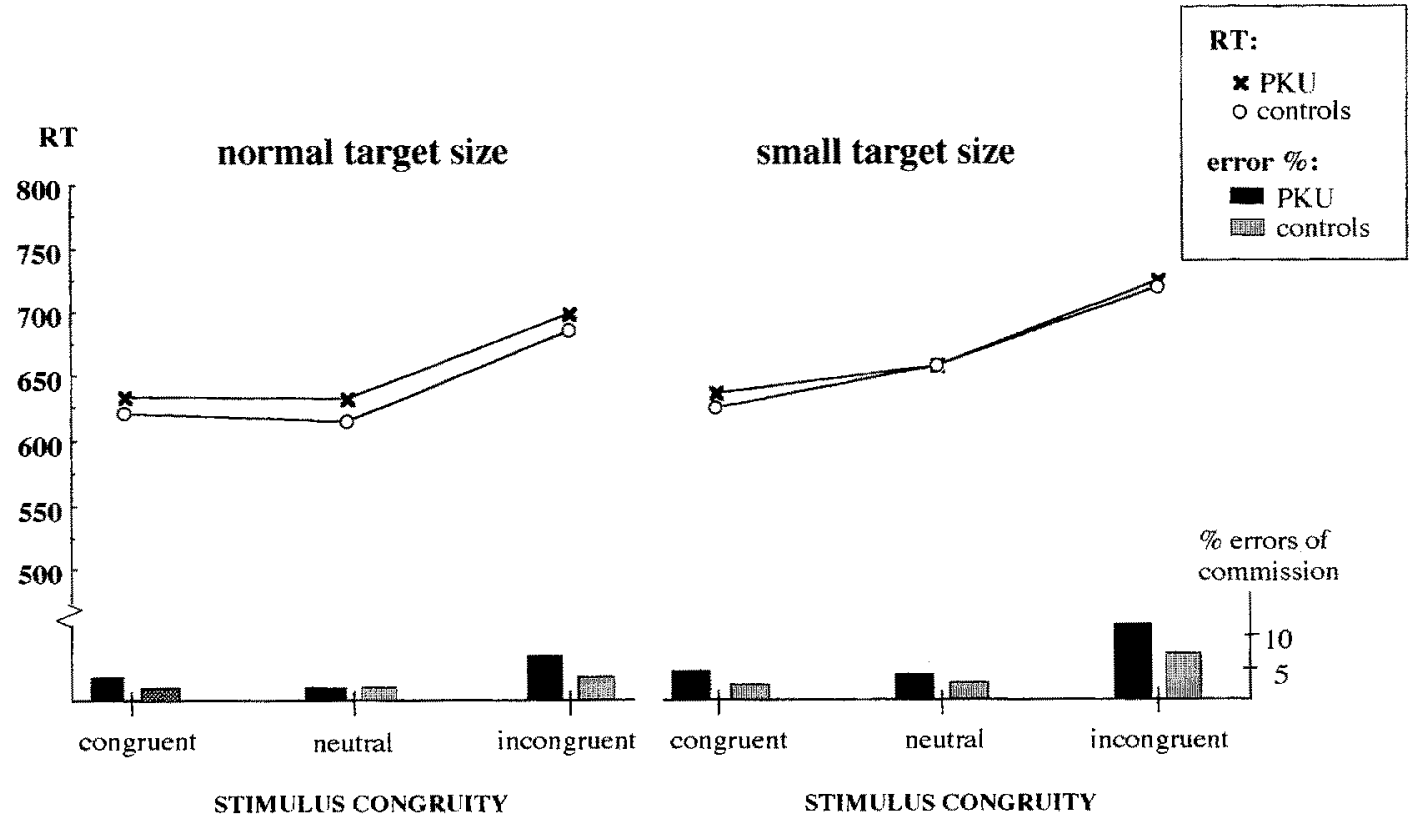

Fig. 1 Mean response time and errors for both groups on the Erikson and Schultz task. The results for the normal and the small target size condition are presented in the left and right panel respectively

\section{Results}

General level of intelligence and negative task orientation

A pairwise comparison of the groups (Table 3) showed that groups did not differ in Full Scale IQ or Performance IQ. Groups differed marginally on Verbal IQ. Furthermore, ratings on negative task orientation did not differ significantly between groups.

\section{Eriksen and Schultz task performance}

As expected, response congruity had a pronounced effect on task performance: mean response times in the incongruent response condition were slower $(\mathrm{F}(2,128)=237.29$, $P<0.0001)$ and error percentages higher $(\mathrm{F}(2,128)=$
$50.97, P<0.0001)$, compared to the congruent and neutral response conditions. Manipulation of target size led to a significant increase in both mean response time $(F(1,64)=$ $15.75, P<0.0001)$ and error percentages $(\mathrm{F}(1,64)=6.60$, $P<0.005$ ), in the incongruent and neutral response conditions, but not in the congruent condition. Most importantly, the PKU patients and the controls did not differ in mean response time $(\mathrm{F}(1,64)=0.12, P=0.73)$ and error percentages $(\mathrm{F}(1,64)=2.42, P=0.13)$. Finally, the effects of stimulus congruity and target size did not discriminate between groups $(\mathrm{F}(2,128)=0.69, P=0.50$ and $\mathrm{F}(1,64)=$ $0.62, P=0.43$, respectively).

\section{Memory search task performance}

The results of this task are summarized in Fig. 2. The left panel shows the mean response time and the percentage of incorrect yes/no responses for both groups in the baseline condition. The right panel shows the mean response time and number of incorrect yes/no responses for both groups in the experimental condition. Memory load had a strong effect on response speed and error rate $(F(1,62)=216.99$, 
Fig.2 Mean response time and incorrect yes/no response for both groups on the memory search task
50-50 condition

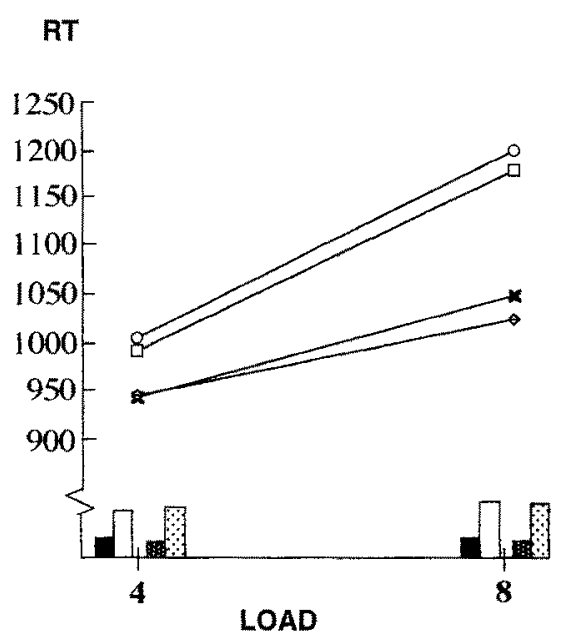

25-75 condition

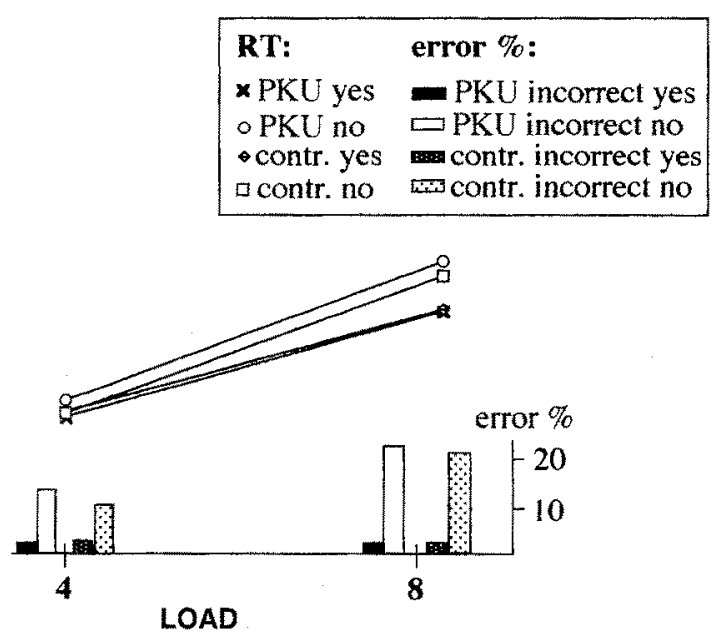

$P<0.0001$ and $\mathrm{F}(1,62)=30.61, P<0.0001$, respectively). Furthermore, the within-subjects variability and the number of omissions increased as the memory load increased $(\mathrm{F}(1,62)=22.70, P<0.0001$ and $\mathrm{F}(1,62)=42.04$, $P<0.0001$, respectively).

Response probability also had a considerable effect on response speed $(\mathrm{F}(1,62)=29.37, P<0.0001)$ and the number of incorrect no-responses $(\mathrm{F}(1,62)=34.09, P<$ 0.0001 ), that is, frequent no-responses were made faster than infrequent yes-responses and more incorrect no-responses were made in the experimental compared to the baseline condition. Groups did not differ in mean response time $(F(1,62)=0.06, P=0.81)$, number of incorrect yes/no responses $(\mathrm{F}(1,62)=0.55, P=0.46)$, withinsubjects variability $(\mathrm{F}(1,62)=0.01, P=0.93)$, or number of omissions $(\mathrm{F}(1,62)=0.00, P=0.99)$. Most importantly, the effects of memory load $(\mathrm{F}(1,62)=0.24, P=0.62$; $\mathrm{F}(1,62)=0.03, P=0.87)$ and response probability $(\mathrm{F}(1,62)=0.31, P=0.58 ; \mathrm{F}(1,62)=0.82, P=0.37) \mathrm{did}$ not discriminate between $P K U$ patients and normal controls on mean response time or number of incorrect yes/no responses respectively, nor on any of the other dependent variables.

Stimulus interval task performance

Figure 3 shows the mean response time and percentage of incorrect responses, for both groups, over the three ISI conditions. ISI strongly affected task performance: the shorter the interval, the faster the mean response time $(\mathrm{F}(2,120)=144.40, P<0.0001)$, the smaller the withinsubject variability $(\mathrm{F}(2,120)=7.26, P=0.001)$, and the greater the number of incorrect responses $(\mathrm{F}(2,120)=$ $9.75, P<0.0001$ ). The number of (incorrect) responses to catch trials was larger in the two exteme interval conditions, than in the medium condition $(\mathrm{F}(2,120)=8.28, P<$ 0.0001 ). As can be seen from Fig. 3 , the mean response

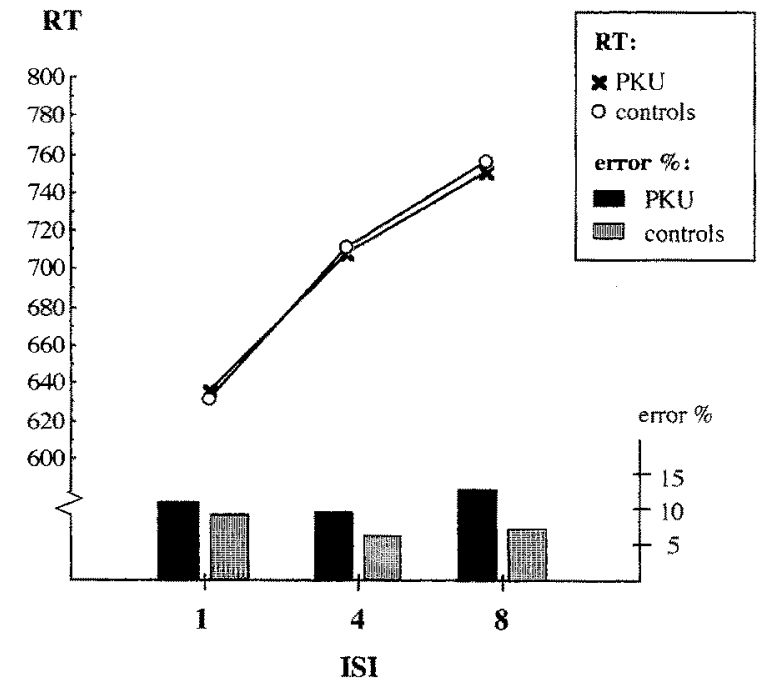

Fig. 3 Mean response time and errors of commission for both groups on the stimulus interval task

times of the two groups were practically identical $(\mathrm{F}(1,60)$ $=0.00, P=0.96$ ). However, patients in the PKU group made significantly more errors, and responded somewhat more frequently to catch stimuli than controls $(\mathrm{F}(1,60)=$ $12.05, P<0.001$, and $\mathrm{F}(1,60)=3.23, P=0.08$ respectively). This pattern appeared irrespective of the stimulus interval condition, however $(\mathrm{F}(2,120)=1.02, P=0.36$ and $\mathrm{F}(2,120)=0.04, P=0.96)$.

Phe levels and task performance

Correlations were examined between performance measures and blood Phe levels within the PKU group. Because age influenced both Phe levels and task performance (the older the subject, the higher the Phe levels and the better the task performance), we controlled for age 
Table 4 Partial correlation coefficients (controlling for age) between Phe levels and performance measures (response speed and inaccuracy)

$* P<0.05$

\begin{tabular}{|c|c|c|c|c|c|c|}
\hline & \multicolumn{2}{|c|}{$\begin{array}{l}\text { Eriksen and Schultz } \\
\text { task }\end{array}$} & \multicolumn{2}{|c|}{$\begin{array}{l}\text { Memory search } \\
\text { task }\end{array}$} & \multicolumn{2}{|c|}{$\begin{array}{l}\text { Stimulus interval } \\
\text { task }\end{array}$} \\
\hline & RT & Error $\%$ & RT & Error \% & RT & Error \% \\
\hline \multicolumn{7}{|l|}{ First 4 years: } \\
\hline Mean Phe & $0.33^{*}$ & -0.004 & 0.03 & 0.12 & 0.23 & -0.03 \\
\hline$\%$ Phe $<120$ & 0.17 & 0.05 & 0.11 & 0.25 & 0.20 & $0.38 *$ \\
\hline$\%$ Phe $<200$ & 0.02 & -0.06 & 0.09 & 0.002 & -0.10 & 0.18 \\
\hline$\%$ Phe $>480$ & $0.37^{*}$ & 0.02 & 0.06 & 0.07 & 0.20 & -0.07 \\
\hline$\%$ Phe $>600$ & $0.39 *$ & -0.07 & 0.08 & 0.03 & 0.16 & -0.02 \\
\hline \multicolumn{7}{|c|}{2 years before testing: } \\
\hline Mean Phe & $0.33^{*}$ & -0.08 & 0.03 & -0.07 & 0.26 & 0.08 \\
\hline$\%$ Phe $<120$ & -0.07 & 0.04 & 0.01 & -0.11 & -0.08 & -0.01 \\
\hline$\%$ Phe $<200$ & -0.11 & 0.16 & -0.06 & -0.06 & -0.09 & 0.07 \\
\hline$\%$ Phe $>480$ & 0.21 & -0.15 & -0.01 & -0.09 & 0.20 & 0.08 \\
\hline$\%$ Phe $>600$ & $0.31 *$ & -0.13 & -0.09 & -0.17 & 0.13 & 0.03 \\
\hline
\end{tabular}

when examining the relation beween Phe measures and performance measures. Table 4 shows that in the Eriksen and Schultz task five different Phe levels correlated significantly and positively with response speed. These measures were: mean Phe level in the first 4 years, percentage of Phe levels above $480 \mu \mathrm{mol} / 1$ and $600 \mu \mathrm{mol} / 1$ in the first 4 years, and mean Phe level and percentage of Phe levels above $600 \mu \mathrm{mol} / \mathrm{l}$ in the 2 years preceding the day of testing. These correlation coefficients indicate hat higher Phe levels were associated with a slower task performance. No significant correlations between the biochemical data and performance measures were found in the memory search task. In the stimulus interval task the percentage of Phe levels $<120 \mu \mathrm{mol} / 1$ in the first 4 years correlated significantly and positively with task inaccuracy, indicating that a higher (lower) percentage of low Phe levels was associated with a higher (lower) percentage of errors.

\section{Discussion}

The results of the present study suggest that deficits in elementary information processing are not manifested among early-treated PKU patients who had been continuously maintained on a Phe-restricted diet, at least not on the measures used here. In fact, the overall performance of patients with early and continuously-treated PKU practically matched that of the controls in all three tasks. Furthermore, no differences were found between the two groups with respect to mean IQ or task oriented behaviour. The only significant difference was found on the stimulus interval task, in which PKU patients made more errors than controls. As this difference was independent of the stimulus interval manipulation it could not be interpreted in terms of an inability to preset a response.

Although these findings may seem inconsistent with the results of earlier studies which showed that PKU pa- tients perform more slowly and/or less accurately than controls in a variety of information processing tasks $[1,3$, $5,6,7,14,28,291$, it will be argued that this is not necessarily true. First, most of the studies that have found differences between PKU patients and controls included PKU patients that had been off the Phe-restricted diet for some time or had relatively poor dietary control $[1,3,5,6$, 14]. Secondly, a number of studies have shown that task efficiency depends critically on dietary control $[6,14,29]$. For instance, de Somneville et al [29] demonstrated that differences in task performance between PKU patients and controls could be attributed solely to a group of patients with Phe levels $>600 \mu \mathrm{mol} / \mathrm{l}$ whereas the performance of patients with Phe-levels $\leq 600 \mu \mathrm{mol} / 1$ actually matched that of the controls. Our sample of PKU patients had been continuously maintained on a well-controlled Phe-restricted diet, resulting in average Phe levels that were low compared to the levels generally mentioned in the literature $[1,3,5,6,7,14]$. Although the number of patients in our sample with Phe levels $>600 \mu \mathrm{mol} / 1$ was too small to permit a comparison between patients with "good" and patients with "poor" control (as was done by de Sonneville et al [29]), it seems reasonable to assume that the low Phe levels found in our patient group have indeed contributed to the absence of group differences in the present study. These low Phe levels in combination with the small range of the Phe levels, may also have prevented strong correlations between biochemical data and performance measures.

An issue that deserves attention is the fact that we have excluded $\mathrm{PKU}$ patients with an IQ $<70$ from participation in this study. It could be argued that by excluding these patients we may have precluded the possibility of finding any group differences. This argument does not seem plausible, however, since only 3 patients from an original sample of 58 were excluded because of this criterion, Additionally, in some of the studies that have found PKU pa- 
tients and controls to perform more slowly and/or less accurately than controls on speeded performance tasks, groups were actually matched for IQ $[1,6,7]$, whereas we only limited the range of IQs for both groups. Furthermore, average intelligence does not rule out specific cognitive deficits [31].

The present findings seem to support the recommendations of the Medical Research Council Working Party Phenylketonuria for stricter dietary control aiming at an upper limit of $480 \mu \mathrm{mol} / \mathrm{l}$ in school age children $[15,16]$. First, PKU patients who were treated under these recommended dietary conditions performed equally well as a matched control group on tasks measuring perceptual, central, and response-related aspects of information processing. Secondly, although groups were not matched according to IQ, they did not differ in Full Scale IQ. A find-ing which is consistent with that of Ris et al [22] who showed that the mean IQ scores of adult patients who had continuously adhered to the stringent dietary restrictions were virtually indistinguishable from the scores of their unaffected sibling. Thirdly, the significant correlation between task performance on the Eriksen and Schultz task and Phe levels suggests that even within a sample of relatively well-controlled PKU patients performance can be improved by stricter dietary control. Finally, PKU patients in our sample received similar ratings as controls on task oriented behaviour.

In line with Ris et al [22] it may be argued that the usual projections of low average intellectual development and poor performance on a variety of speeded performance tasks for PKU patients who are treated early may underestimate their potential under conditions of more optimal dietary control. It is acknowledged, however, that the tasks used in this study do not provide an exhaustive measurement of cognitive functioning, as they primarily assessed elementary mechanisms of information processing. Therefore, we cannot comment on the effectiveness of stricter dietary control in preventing deficits in higherorder cognitive processes. To obtain a more complete evaluation of the potential of PKU patients under more optimal dietary conditions and considering the recent findings that young PKU patients have specific deficits in the prefrontal lobe functions despite continuous treatment $[8,31]$, subsequent investigations will be aimed at studying higher-order cognitive processes in our sample of PKU patients.

Acknowledgement The authors would like to thank Dr. E. J. Stoffels for his help and advice on the construction of the tasks.

\section{References}

1. Anderson VE, Siegel FS, Fisch RO, Wirt RD (1969) Responses of phenylketonuric children on a Continuous Performance Test. J Abnorm Psychol $74: 358-362$

2. Brookhuis KA, Mulder G, Mulder LJM, Gloerich ABM (1983) The P3 complex as an index of information processing: The effects of response probability. Biol Psychol 17:277-296

3. Brunner RL, Berry HK (1987)

Phenylketonuria and sustained attention: the Continuous Performance Test. Int J Clin Neuropsychol 9:68--70

4. Brunner RL, Jordan MK, Berry HK (1983) Early-treated phenylketonuria: neuropsychologic consequences. J Pediatr 102:831-835

5. Brunner RL, Berch DB, Berry HK (1987) Phenylketonuria and complex spatial visualization: an analysis of information processing. Dev Med Child Neurol $29: 460-468$

6. Clarke JTR, Gates RD, Hogan SE, Barre M, MacDonald W (1987) Neuropsychological studies on adolescents with phenylketonuria returned to phenylalanine-restricted diets. Am J Ment Ret 92:255-262
7. Craft S, Gourovitch ML, Dowton SB, Swanson JM, Bonforte S (1992) Lateralized deficits in visual attention in males with developmental dopamine depletion. Neuropsychologia 30 : 341-351

8. Diamond A, Hurwitz W, Lee EY, Bockes T, Grover W, Minarcik C (1994) Cognitive deficits on frontal cortex tasks in children with early treated PKU: results of two years of longitudinal study (in press)

9. Eriksen CW, Schultz DW (1979) Information processing in visual search: a continuous flow conception and experimental results. Perc Psychophysiol 25 : 249-263

10. Huisman J, Slijper FME, Hendrikx MMT, Kalverboer AF, Schot L van der (1985) Development of the intellect of phenylketonuria patients; 15 years" nationwide screening in the Netherlands (in Dutch). Ned Tijdschr Geneeskunde 136:2277-2281

11. Kalverboer AF, Schot L van der, Hendrikx MMH, Huisman J, Slyper FME, Stemerdink BA (1994) Social behavior and task orientation in early-treated PKU. Acta Paediatr Scand 83 [Suppl] 407:104-105
12. Kalverboer AF, Stemerdink BA, Siebelink BM, Treffers PDA (1994) A School Behaviour Questionnaire (the GBS short) for screening and clinical purposes.

13. Koch R, Azen CG, Hurst N, GrossFreidman E, Fishler K (1987) The effects of diet discontinuation in children with phenylketonuria. Eur J Pediatr 146 [Suppl 1]: A12-A16

14. Lou HC, Lykkelund C, Gerdes AM, Udesen H, Bruhn P (1987) Increased vigilance and dopamine synthesis by large doses of tyrosine or phenylalanine restriction in phenylketonuria. Acta Paediatr Scand 76:560-565

15. Medical Research Council Working Party Phenylketonuria (1993) Phenylketonuria due to phenylalanine hydroxylase deficiency: an unfolding story. BMJ 306:115-119

16. Medical Research Council Working Party Phenylketonuria (1993) Recommendations on the dietary management of phenylketonuria. Arch Dis Child 68: 426-427

17. Meere JJ van der, Baal M van, Sergeant JA (1989) The additive factor method: A differential tool in hyperactivity and learning disability. I Abn Child Psychol 17:409-422 
18. Meere JJ van der, Vreeling HJ, Sergeant JA (1992) A motor presetting study in hyperactive, learning disabled and control children. J Child Psychol Psychiatry 33:1347-1354

19. Mulder G (1983) The information processing paradigm: concepts, methods and limitations. J Child Psychol Psychiatry $24: 19-35$

20. Pennington $\mathrm{BF}$, Doorninck WJ van, McCabe LL, McCabe ERB (1985) Neuropsychological deficits in earlytreated phenylketonuretic children. Am J Ment Def 89:467-474

21. Ridderinkhof KR (1993) Interference from irrelevant information. $\mathrm{PhD}$ Thesis. University of Amsterdam

22. Ris MD, Williams SE, Hunt MM, Berry HK, Leslie N (1994) Earlytreated phenylketonuria: Adult neuropsychologic outcome. J Pediatr 124 : $388-392$
23. Saudubray JM, Rey F, Ogier H, Abadie V, Farriaux JP, Ghisholfi J, Guibaud P, Rey J, Vidailhet M (1987) Intellectual and schoolperformances in early-treated classical PKU patients. The French Collaborative Study. Eur J Pediatr 146 [Suppl 1]: A20-A22

24. Seashore MR, Friedman E, Novelly RA, Bapat V (1985) Loss of intellectual function in children with phenylketonuria after relaxation of dietary phenylalanine restriction. Pediatr $75: 226-232$

25. Smith I, Beasley MG (1989) Intelligence and behaviour in children with early treated phenylketonuria. Eur $J$ Clin Nutr $43: 1-5$

26. Smith I, Beasley MG, Wolff OH, Ades $\mathrm{AE}$ (1988) Behavior disturbance in 8year-old children with early-treated phenylketonuria. J Pediatr 112: 403-408
27. Smith I, Beasley MG, Ades AE (1990) Effect on intelligence of relaxing the low phenylalanine diet in phenylketonuria. Arch Dis Child $65: 311-316$

28. Sonneville LNJ de, Schmidt E, Michel U (1989) Information processing in early treated PKU. J Clin Exp Neuropsychol $11: 362$

29. Sonneville LMJ de, Schmidt E, Michel U, Batzler U (1990) Preliminary neuropsychological test results. Eur J Pediatr 149 [Suppl 1]: S39-\$44

30. Sternberg $S$ (1969) The discovery of processing stages; extensions of Donders' Method. Acta Psychol 8: 276-315

31. Welsh $\mathrm{MC}$, Pennington $\mathrm{BF}$, Ozonoff $\mathrm{S}$, Rouse B, McCabe ERB (1990) Neuropsychology of early-treated phenylketonuria: specific executive function deficits. Child Dev 61 : $1697-1713$ 